\title{
Self-Assembly Effects of Seafood Waste and Cow Dung to Remediate Saline Soil
}

\author{
Kejun Wen1,2, Cong Liu1,2*, Liping Wu1,2, Chao Ma1,2, Yuyao Zhang1,2 \\ ${ }^{1}$ Tianjin Chengjian University, School of Environmental and Municipal Engineering, Tianjin, China \\ ${ }^{2}$ Tianjin Key Laboratory of Aquatic Science and Technology, Tianjin, China \\ Email:
}

Received 2 June 2015; accepted 15 August 2015; published 18 August 2015

Copyright (C) 2015 by authors and Scientific Research Publishing Inc.

This work is licensed under the Creative Commons Attribution International License (CC BY).

http://creativecommons.org/licenses/by/4.0/

(c) (i) Open Access

\section{Abstract}

This research is based on the $U_{8}\left(4^{3}\right)$ uniform table to conduct uniform experiments for improving saline soil. Different proportions of saline soil and silt, with a composted residue of marine fish and seashells that was mixed with sawdust and cow dung, were chosen as the assembly factors. The improvement coefficients for available nitrogen phosphorus of the mixed salt mud and for the production of tall fescue hay were adopted as the characterization values. According to the causal relations that were previously established by 64 types of permutations and combinations, the optimal assembly scheme with maximum characterization values was determined. The results indicate that the artificial soil that consisted of saline soil and silts in a ratio of 8:2; sea fish waste, shellfish trash and sawdust in a ratio of 5:4:1; and $8 \mathrm{~kg}$ of cow dung (10 wt\%) is the best among the 64 types of composting treatments. Under the improved conditions, the predictive values of the increasing coefficients of valid nitrogen and valid phosphorus in the soil are 1.99 and 1.93 , respectively; the predictive value of the tall fescue in a unit area production is $238.83 \mathrm{~g} \cdot \mathrm{m}^{-2}$. Its error accuracy is more than $99.82 \%$. All of the above results indicate that utilizing the saline soil improvement media, which is composed of Haihe river silts, fish and shellfish slag, cow dung, and other wastes, provides a new option for saline soil improvement.

\section{Keywords}

Haihe Estuary Sediments, Seafood Residue, Coastal Saline Soil Improvement, Regression Analysis

\section{Introduction}

Soil is one of the key elements of environmental systems [1] [2]. Thus, soil pollution protection is fundamental

"Corresponding author. 
for most productive activities [3]. The salinization of soils, which has become a widespread nature hazard because of serious land degradation, has become a major barrier to local agriculture production and a major concern worldwide that researchers have sought to improve [4]-[7]. The salinization of soils is a natural phenomenon, particularly in coastal areas due to seawater intrusion or high-salt groundwater discharge [8] [9]. The low productivity of saline soils may be ascribed not only to their salt toxicity or to damage caused by excess amounts of soluble salts but also to the lack of organic matter and available mineral nutrients, particularly N, P, and K [10]. Concerns regarding salinization risks, environmental quality and agro-ecosystem productivity have emphasized the requirement of developing management practices that maintain soil resources [11]. Many previous studies have involved analyses and made some effective attempts to solve this problem, which is greatly affecting agricultural areas. To enhance soil productivity in agricultural lands and to rebuild fertility, composted municipal solid waste has commonly been used [12] [13]. In 2006, two organic wastes (cotton gin-crushed compost and poultry manure) were added into saline soil in dry land conditions and their effects on the soil were studied over a period of 5 years [14]. To study the methane emission effects of the addition of a locally available organic and fresh green manure to saline soil, a field experiment was conducted using morning glory as a potential green manure to increase the grain yield of coastal saline ecosystems [15].

Much sediment under the estuary of the Haihe River needs to be cleared annually [16] [17]. This sludge contains many proteases, fatty acids, amino acids, chitosan, and many minerals; many dominant species that live in this region have the ability to alternately survive in seawater and in freshwater environments [18] [19]. The marine fish and shellfish residue that is generated by the seafood market, to which many microorganisms attach, has not been effectively utilized for coastal saline soil. This residue not only pressures the environment but also wastes resources. In this paper, the authors present the effects of the application of a composted residue of marine fish and seashells, which was mixed with sawdust, Haihe estuary sediments and cow dung, on the fertility characteristics of coastal saline soil. Different proportions of saline soil and silt with composted residue of marine fish and seashells that were mixed with sawdust, amounts of cow dung and the structural component of Festuca arundinacea were tested using a uniform experiment to examine whether this mixture can rebuild the ecological structure of saline soil via self-assembly and self-repair by the biological structure (containing indigenous organisms in saline soil), which is specific for improving saline soil and its trophic structure. To provide the foundation and theory for the improvement of saline soil by this method, the improvement coefficients of available nitrogen and available phosphorus in the saline soil after the implementation of this method and the shoot dry weight of the harvest of Festuca arundinacea were used as representations of the achievement and inquiry into the correlation between these assembly factors and their characterization values. As one of the most important conclusions, the optimal proportion scheme was found at last.

\section{Methods}

\subsection{Test Conditions}

The saline soil that was used in this study was taken from the Binhai Aircraft. The salty soil is raw bentonite, whose sampling range extends from the surface to $0.4 \mathrm{~m}$ underground, with a total salt content of $18.00 \mathrm{~g} \cdot \mathrm{kg}^{-1}$ and conductivity of $7.20 \mathrm{dS} \cdot \mathrm{m}^{-1}$. The nutrient and salt content are shown in Table 1 . According to the sampling value, the shallow layer simulates the groundwater salinity composition, which is shown in Table 2 . The dredging sediment that was collected downstream from the Haihe River was called Haihe estuary sediment, whose nutrient and mineral composition are shown in Table 3. Ceramic flowerpots (height $0.26 \mathrm{~m}$, diameter $0.30 \mathrm{~m}$, volume $0.018 \mathrm{~m}^{3}$ ) were used as treatment devices for this uniform experiment. The U8 $\left(4^{3}\right)$ uniform table is shown in Table 4. Each flowerpot is an independent processing unit, each eight processing units were considered a test group, with each test group set up twice as parallel tests, and 2 flowerpots that were filled with the original saline soil were set as the controlled trial. Thus, 26 flowerpots were used for this experiment. Water holes were added to the bottoms of the flowerpots. The structure of each processing unit was prepared as follows from the bottom of the flowerpot: first, a $6 \mathrm{~cm}$ stone layer was set to simulate the groundwater layer (particle size 2 - $4 \mathrm{~cm}$, flowerpot volume $0.004 \mathrm{~m}^{3}$ ); second, a permeable nonwoven fabric was installed; third, different ratios of the test filler were used to fill the pots; then, seeds of Festuca arundinacea were planted in the filler and covered with a thin layer of river sand. Finally, the processing unit was placed in the flume. The flume, whose depth is $6 \mathrm{~cm}$, can prevent evaporation; therefore, the flume was used to simulate the groundwater level. The erection of a Mariotte flask kept the groundwater level stable and helped to measure the volume of water 
Table 1. Content of nutrients and salt ions in saline soil.

\begin{tabular}{|c|c|c|c|c|c|c|c|c|c|}
\hline \multicolumn{3}{|c|}{ Nutrient content $/\left(\mathrm{g} \cdot \mathrm{kg}^{-1}\right)$} & \multicolumn{7}{|c|}{ Salt ions content $/\left(\mathrm{g} \cdot \mathrm{kg}^{-1}\right)$} \\
\hline Organic matter & Valid-N & Valid-P & $\mathrm{Na}^{+}$ & $\mathrm{Mg}^{2+}$ & $\mathrm{Ca}^{2+}$ & $\mathrm{K}^{+}$ & $\mathrm{Cl}^{-}$ & $\mathrm{SO}_{4}^{2-}$ & $\mathrm{HCO}_{3}^{-}$ \\
\hline 30.298 & 16.213 & 3.785 & 4.136 & 0.533 & 1.288 & 0.451 & 3.994 & 2.520 & 5.078 \\
\hline
\end{tabular}

Table 2. Ground water salinity component.

\begin{tabular}{ccc}
\hline Salinity & Molar ratio/\% & Content $/\left(\mathrm{g} \cdot \mathrm{L}^{-1}\right)$ \\
\hline $\mathrm{MgCl}_{2}$ & 13 & 1.49 \\
$\mathrm{Na}_{2} \mathrm{SO}_{4}$ & 14 & 1.95 \\
$\mathrm{CaCl}_{2}$ & 18 & 2.25 \\
$\mathrm{NaCl}$ & 55 & 3.31 \\
\hline
\end{tabular}

Table 3. Nutrient and chemical composition of sediment in sea estuary area.

\begin{tabular}{cccccccccc}
\hline & \multicolumn{3}{c}{ Nutrient composition/\% } & \multicolumn{5}{c}{ Chemical composition mg/kg } \\
\hline Organic matter & TN & TP & Mn & Ni & Cr & Cu & Zn & Cd \\
\hline 1.68 & 0.147 & 0.099 & 678.7 & 169.9 & 620.8 & 269.5 & 1936.5 & 12.2 \\
\hline
\end{tabular}

Table 4. The design of the U8 (43) uniform experiments and their results.

\begin{tabular}{|c|c|c|c|c|c|c|c|c|c|c|c|c|c|c|c|c|}
\hline \multirow[t]{3}{*}{ Number } & \multirow{2}{*}{\multicolumn{4}{|c|}{$\begin{array}{l}\text { The weight ratio of saline } \\
\text { soils and silts and its } \\
\text { fictitious variables }\end{array}$}} & \multirow{2}{*}{\multicolumn{4}{|c|}{$\begin{array}{l}\text { Component ratio } \\
\text { (sea fish waste:shellfish } \\
\text { trash:sawdust) and its } \\
\text { fictitious variables }\end{array}$}} & \multirow{3}{*}{$\begin{array}{c}\begin{array}{c}\text { cow } \\
\text { dung } \\
/ \mathrm{kg}\end{array} \\
X_{3}\end{array}$} & \multicolumn{3}{|c|}{$\begin{array}{l}\text { Improvement } \\
\text { coefficient of } \\
\text { available nitrogen }\end{array}$} & \multicolumn{3}{|c|}{$\begin{array}{c}\text { Improvement } \\
\text { coefficient of } \\
\text { available phosphorus }\end{array}$} & \multirow{3}{*}{$\begin{array}{c}\begin{array}{c}\text { Dry weight } \\
\text { of Festuca } \\
\text { unit }\end{array} \\
\text { area/ }\left(\mathrm{g} \cdot \mathrm{m}^{-2}\right) \\
Y_{L}\end{array}$} \\
\hline & & & & & & & & & & 1 & 2 & 3 & 1 & 2 & 3 & \\
\hline & $X_{1}$ & $X_{11}$ & $X_{12}$ & $X_{13}$ & $X_{2}$ & $X_{21}$ & $X_{22}$ & $X_{23}$ & & & $Y_{N}$ & & & $Y_{P}$ & & \\
\hline 1 & $9: 1$ & 1 & 0 & 0 & $8: 1: 1$ & 0 & 1 & 0 & 0.8 & 1.43 & 1.45 & 1.46 & 1.32 & 1.34 & 1.35 & 172.66 \\
\hline 2 & $9: 1$ & 1 & 0 & 0 & $7: 2: 1$ & 0 & 0 & 0 & 0.5 & 1.32 & 1.29 & 1.31 & 1.21 & 1.18 & 1.20 & 180.23 \\
\hline 3 & $8: 2$ & 0 & 1 & 0 & $8: 1: 1$ & 0 & 1 & 0 & 0.2 & 1.27 & 1.26 & 1.25 & 1.16 & 1.15 & 1.14 & 154.21 \\
\hline 4 & $8: 2$ & 0 & 1 & 0 & $7: 2: 1$ & 0 & 0 & 0 & 0 & 1.19 & 1.18 & 1.16 & 1.09 & 1.08 & 1.05 & 165.08 \\
\hline 5 & $7: 3$ & 0 & 0 & 1 & $6: 3: 1$ & 0 & 0 & 1 & 0.8 & 1.48 & 1.47 & 1.49 & 1.37 & 1.36 & 1.38 & 153.27 \\
\hline 6 & $7: 3$ & 0 & 0 & 1 & $5: 4: 1$ & 1 & 0 & 0 & 0.5 & 1.38 & 1.39 & 1.35 & 1.27 & 1.28 & 1.24 & 172.66 \\
\hline 7 & $6: 4$ & 0 & 0 & 0 & $6: 3: 1$ & 0 & 0 & 1 & 0.2 & 1.25 & 1.27 & 1.26 & 1.14 & 1.16 & 1.15 & 192.04 \\
\hline 8 & $6: 4$ & 0 & 0 & 0 & $5: 4: 1$ & 1 & 0 & 0 & 0 & 1.23 & 1.24 & 1.23 & 1.12 & 1.13 & 1.12 & 214.26 \\
\hline
\end{tabular}

consumption and water permeability.

\subsection{Ratio of Trial Soil}

Before implementing composting, these marine fish and seashell residues were mixed with sawdust according the four ratios that are shown in Table 4. To reserve after composting, the compost was dug up. Then, the saline soil, sediment and the compost, which was composed of fish residue, shellfish residue, sawdust and cow dung, were mixed and reserved. According to the eight assembly types, the matrix was prepared, which was formed by different ratios of saline soil, marine fish and seashell residues, sawdust and cow dung, as shown in Table 4. In particular, 12 kilograms of the corresponding compost and the sediment and saline soil mixture were first uniformly mixed into 24 kilograms ( $8 \mathrm{~kg} /$ basin; the volume of the actual test soil was $0.013 \mathrm{~m}^{3}$ ), then, $2.4 \mathrm{~kg}$ 
(10\%), $1.5 \mathrm{~kg}$ (6.25\%), $0.6 \mathrm{~kg}(2.5 \%)$ and $0 \mathrm{~kg}$ cow dung were added based on test numbers, and the corresponding 24 flowerpots were filled with the matrix after thorough blending to complete the eight assembly types and the preparation of triplicates of each type for a uniform experiment.

\subsection{Sowing and Data Acquisition}

At the beginning of April 2001, the flowerpots were filled with the test soil and the plants were sown. Festuca arundinacea, which has strong vitality, stress resistance against saline-alkaline and more than $85 \%$ germination for planting, was selected. Its seeding rate is $1.32 \mathrm{~g} /$ basin $\left(20 \mathrm{~g} \cdot \mathrm{m}^{-2}\right)$. The detection period was from the beginning of May to the end of September. To reduce the hysteretic nature of soil nutrients, the hysteretic value was determined by examining the effects of the perturbation of the test matrix and soil adsorption, employing the saturated water content of the experimental substrate as a reference, and by directly determining the soil available nitrogen and phosphorus in water samples as an index of this test. Indophenol blue colorimetry was used to measure the ammonium nitrogen in the test soil, and ultraviolet spectrophotometry was used to measure the nitrate nitrogen in the test soil. The molybdenum blue colorimetric method was used to determine the phosphorus content in the improved saline soil. The first measurement was at seven days and measurements were taken again after thirty days. To reduce artificial errors, sample measurements were repeated three to five times for each sample, and the average of three similar values was considered the measured value of the sample. Tall Festuca arundinacea was produced at the end of September, by the end of the experiment. The aerial part of Festuca arundinacea was harvested from every experimental plot, dried and weighed. Finally, the average of three replicates for Festuca arundinacea production in each processing unit was determined.

\section{Treatment and Analysis of Test Data}

\subsection{Data Processing}

For the determination of the soil available nitrogen and available phosphorus values, the time series data of dynamic change over time were used, with the chronological average as a representation of the entire process for the dependent variable. The available nitrogen and available phosphorus chronological averages of each test group of three replicates of each time series, were first calculated, and then the ratio of the chronological average of time series, which is the ratio of the available nitrogen and phosphorus of a test group compared with that of 2 control groups, was calculated and used as the target $(\mathrm{Y})$ of regression analysis. Because the survival rate of Festuca arundinacea in the control group is zero, the average of the measured Festuca arundinacea dry weight, which is the average value of triplicate trials with dimension $\mathrm{g} \cdot \mathrm{m}^{-2}$, as the characterization value of modified achievement to saline soil were calculated by this method.

The qualitative variables on the U8 $\left(4^{3}\right)$ uniform table were converted to dummy variables for regression analysis. The transformed test data are shown in Table 4.

\subsection{Model and Inspection}

\subsubsection{Regression Model}

According to Table 4, using the PASW Statistics 18 software, the saline soil and sediment ratio $\left(X_{1}\right)$, compost composition ratio $\left(X_{2}\right)$ and the addition of cow dung $\left(X_{3}\right)$ as the independent variables of the assembly control factor, with the improvement coefficient of soil available nitrogen $\left(Y_{N}\right)$, the improvement coefficient of soil available phosphorus $\left(Y_{p}\right)$ and the production of Festuca arundinacea $\left(Y_{L}\right)$ as the dependent variables, a multiple linear regression model was produced as follows:

The regression forecasting model of the improvement coefficient of soil available nitrogen:

$$
Y_{N}=0.962+0.217 X_{12}-0.196 X_{13}+0.268 X_{21}-0.059 X_{22}+0.164 X_{23}+0.683 X_{3}\left(R^{2}=0.987\right)
$$

The regression forecasting model of the improvement coefficient of soil available phosphorus:

$$
Y_{p}=0.836+0.239 X_{12}-0.214 X_{13}+0.285 X_{21}-0.071 X_{22}+0.172 X_{23}+0.717 X_{3}\left(R^{2}=0.986\right)
$$

The regression forecasting model of the Festuca arundinacea dry weight: 


$$
Y_{L}=164.964+0.057 X_{12}-57.042 X_{13}+49.355 X_{21}-16.882 X_{22}+20.887 X_{23}+30.65 X_{3}\left(R^{2}=0.996\right)
$$

The $R^{2}$ value of each regression model indicated that each of the dependent variables and each assembly factor have an extremely high degree of linear fitting, with an extremely high $R^{2}$ value for assembly factors; thus, their correlation is extremely significant.

\subsubsection{Partial Regression Coefficient Test}

Using the $R^{2}$ test, $t$ detection and sig detection of the partial regression of each assembly factor were counted. The contribution degree and significant values are shown in Table 5.

\subsubsection{The Inspection of Prediction Accuracy}

1) The predictive values and measured values were examined as follows: Calculate the predictive value of the improvement coefficient of available nitrogen. Use the improvement coefficient of available nitrogen of the matrix of the sixth group in Table 4 as an example. In the regression model (1), treat the virtual variable $\left(X_{i j}\right)$ that has not been selected as zero, and treat the virtual variable $\left(X_{i j}\right)$ that has been selected as one. Take the corresponding assembly factor in the regression model. The predicted value is as follows:

$$
Y_{N 6}=0.962+(0.217 \times 0)-0.196 \times 1+0.268 \times 1-0.059 \times 0+0.164 \times 0+0.683 \times 0.5=1.3755
$$

\begin{tabular}{|c|c|c|c|c|c|c|c|}
\hline Targets & Factors & $\begin{array}{l}\text { Unstandardized } \\
\text { coefficients* }\end{array}$ & $\begin{array}{l}\text { Standardized } \\
\text { coefficients }\end{array}$ & $\begin{array}{l}\text { Contribution } \\
\text { order }\end{array}$ & t-Value & Sig. ${ }^{* *}$ & Significance \\
\hline \multirow[t]{7}{*}{$Y_{N}$} & constant & $0.962(0.059)$ & & & 16.410 & 0.000 & $* * *$ \\
\hline & $X_{12}$ & $0.217(0.062)$ & 0.937 & 3 & 3.536 & 0.003 & $* * *$ \\
\hline & $X_{13}$ & $-0.196(0.062)$ & -0.844 & 6 & -3.184 & 0.005 & $* * *$ \\
\hline & $X_{21}$ & $0.268(0.062)$ & 1.156 & 2 & 4.345 & 0.000 & *** \\
\hline & $X_{22}$ & -0.059 (0.029) & -0.255 & 5 & -2.053 & 0.056 & $*$ \\
\hline & $X_{23}$ & $0.164(0.035)$ & 0.707 & 4 & 4.740 & 0.000 & $* * *$ \\
\hline & $X_{3}$ & $0.683(0.111)$ & 2.061 & 1 & 6.160 & 0.000 & $* * *$ \\
\hline \multirow[t]{7}{*}{$Y_{P}$} & constant & $0.836(0.061)$ & & & 13.627 & 0.000 & $* * *$ \\
\hline & $X_{12}$ & $0.239(0.064)$ & 1.041 & 3 & 3.715 & 0.002 & $* * *$ \\
\hline & $X_{13}$ & $-0.214(0.064)$ & -0.932 & 6 & -3.326 & 0.004 & $* * *$ \\
\hline & $X_{21}$ & $0.285(0.065)$ & 1.241 & 2 & 4.409 & 0.000 & $* * *$ \\
\hline & $X_{22}$ & $-0.071(0.030)$ & -0.308 & 5 & -2.348 & 0.031 & ** \\
\hline & $X_{23}$ & $0.172(0.036)$ & 0.751 & 4 & 4.758 & 0.000 & $* * *$ \\
\hline & $X_{3}$ & $0.717(0.116)$ & 2.184 & 1 & 6.173 & 0.000 & ${ }^{* * *}$ \\
\hline \multirow[t]{7}{*}{$Y_{L}$} & constant & $164.964(6.126)$ & & & 26.929 & 0.000 & ${ }^{* * *}$ \\
\hline & $X_{12}$ & $0.057(6.427)$ & 0.001 & 4 & 0.009 & 0.993 & \\
\hline & $X_{13}$ & $-57.042(6.427)$ & -1.303 & 6 & -1.301 & 0.000 & $* * *$ \\
\hline & $X_{21}$ & 49.355 (6.453) & 1.128 & 1 & 7.648 & 0.000 & $* * *$ \\
\hline & $X_{22}$ & $-16.882(3.011)$ & -0.386 & 5 & -5.607 & 0.000 & $* * *$ \\
\hline & $X_{23}$ & 20.887 (3.619) & 0.477 & 3 & 5.772 & 0.000 & ${ }^{* * *}$ \\
\hline & $X_{3}$ & 30.650 (11.590) & 0.490 & 2 & 2.645 & 0.017 & $* *$ \\
\hline
\end{tabular}

Table 5. t-test of partial regression coefficient.

Note: ${ }^{*}$ Standard errors value is in the bracket. ${ }^{*}$ Sig. $<0.01$ shows the most significance**; $0.01<$ Sig. $<0.05$ shows more significance**; $0.05<$ Sig. $<0.1$ shows significance*; Sig. $>0.1$ shows little significance. 
Similarly, using regression models (2) and (3), the predictive value of the improvement coefficient of available nitrogen, whose prediction value is 1.2655, and dry weight of Festuca arundinacea, whose prediction value is $172.597 \mathrm{~g} \cdot \mathrm{m}^{-2}$, can also be obtained. Their measured values are $1.3733,1.2633$ and $172.66 \mathrm{~g} \cdot \mathrm{m}^{-2}$, respectively, and their regression accuracies are all above $99.82 \%$. Thus, the three types of characterization values can be forecasted using the regression model. By this method, the prediction values of the three characterization values can be obtained for the other 63 arrangements of the assemble factors.

2) The regression accuracy of the predictive values and detection values of the optimum assembly were calculated as follows: Based on the unstandardized coefficients in Table 5, choose the assembly parameter of the target value, whose contribution to improvement coefficient of available nitrogen, improvement coefficient of available phosphorus and dry weight of Festuca arundinacea is the best of the 64 arrangements of the assembly factors. For instance, $X_{12}$ (the weight ratio of saline soils and silts of 8:2) $+X_{21}$ (component ratio; sea fish waste, 5: shellfish trash, 4: sawdust, 1 ) $+X_{3}$ (cow dung, $0.8 \mathrm{~kg}$ ). Therefore, we obtain the predictive value as follows: the improvement coefficient of available nitrogen $\left(Y_{N}\right)$ is 1.9934; the improvement coefficient of available phosphorus $\left(Y_{P}\right)$ is 1.9936 and the dry weight of Festuca arundinacea $\left(Y_{N}\right)$ is $238.8296 \mathrm{~g} \cdot \mathrm{m}^{-2}$.

Because the best assembly did not appear in Table 4, a repeatability verification test was simultaneously performed in 2012 to study the reliability of the optimum parameters of the assembly. By the verification results in Table 6, the author found that the improvement coefficients of the soil available nitrogen and soil available phosphorus have a higher goodness of fit with the predictive value than with the dry weight of Festuca arundinacea. Uncontrollable meteorological factors led to the lower dry weight of Festuca arundinacea compared with its predictive value.

\section{Results and Discussions}

The correlation coefficients $\left(R^{2}\right)$ of each regression model are all above 0.986 . This result indicates that there were statistically significant linear relations between the dependent variables and all the assembly factors. The regression analysis results of three models are as follows.

\subsection{Scheduling Problems and the Analysis of the Contribution of Each Factor to the Target Value}

1) The contribution of each factor to the improvement coefficients of available nitrogen and available phosphorous has a high degree of homoplasy. The contribution schedule of each assembly factor for improvement coefficients of available nitrogen and available phosphorous is as follows: $X_{3}$ (cow dung) $>X_{2}$ (component ratio) $>X_{1}$ (weight ratio of saline soils and silts). The contribution schedule of the level of each assembly factor is as follows: $X_{3}$ (cow dung, 0.8) $>X_{21}$ (component ratio, 5:4:1) $>X_{12}$ (weight ratio of saline soils and silts, 8:2) $>$ $X_{23}$ (component ratio, 6:3:1) $>X_{22}$ (component ratio, 8:1:1) $>X_{13}$ (weight ratio of saline soils and silts, 7:3). The influence of $X_{22}$ and $X_{13}$ on nitrogen and phosphorus is a negative correlation, and the influence of $X_{22}$ on the improvement coefficients of available nitrogen and available phosphorus are significant and more significant, respectively. Beyond that, the influence of other assembly factors on the improvement coefficients of available nitrogen and available phosphorus are all positively correlated and very significant.

2) The contribution of each factor to the dry weight of Festuca arundinacea is different from that to the improvement coefficients of available nitrogen and available phosphorous. The contribution schedule of each assembly factor is as follows: $X_{2}$ (component ratio) $>X_{3}$ (cow dung) $>X_{1}$ (weight ratio of saline soils and silts). The contribution schedule of the level of each assembly factor is as follows: $X_{21}$ (component ratio, 5:4:1) $>X_{3}$ (cow dung, 0.8) $>X_{23}$ (component ratio, 6:3:1) $>X_{12}$ (weight ratio of saline soils and silts, 8:2) $>X_{22}$ (component ratio, 8:1:1) $>X_{13}$ (weight ratio of saline soils and silts, 7:3). The influences of $X_{22}$ and $X_{13}$ on the dry weight of

Table 6. Targets of optimum disposing.

\begin{tabular}{ccc}
\hline Target & 1 & 2 \\
\hline Improvement coefficient of available nitrogen & 1.98 & 1.96 \\
Improvement coefficient of available phosphorus & 1.92 & 1.90 \\
Dry weight of Festuca arundinacea $\left(\mathrm{g} \cdot \mathrm{m}^{-2}\right)$ & 231.57 & 230.02 \\
\hline
\end{tabular}


Festuca arundinacea are negatively correlated, and the influence of $X_{12}$ on the dry weight of Festuca arundinacea is not significant. Beyond that, the influences of other assembly factors on the dry weight of Festuca arundinacea are all positively correlated and more significant. This result indicates that the dry weight of Festuca arundinacea is not only correlated with organic fertilizer but also significantly negatively correlated with the content of silts in the test soil.

\subsection{Analysis of Contributions of Each Factor to the Dependent Variable}

1) The contribution of cow dung to the improvement coefficients of available nitrogen and available phosphorous rank first, and its contribution to the dry weight of Festuca arundinacea ranks second. Not only does fermented cow dung contain $60.9 \%$ organic matter, in which there is $30.36 \%$ crude protein and $5.06 \%$ crude fat, but the dung is also rich in vitamins and amino acids. Thus, cow dung contributes to the biosynthesis of humus colloids, and its large granular structure cause the sodium salt of the test soil to obtain a bond bridge to improve the performance of its anions and cations for the synthesis and metabolism of sodium ions so that the cation absorption capacity increases 6 - 10 times compared with that of the original soil. In addition, humic acid and folic acid play a key role of in the mechanism to reduce the activity of soil salinity, to increase the released amounts of nitrogen and phosphorus, which are absorbed and fixed for improving the effectiveness of nitrogen and phosphorus, and to promote the accumulation of photosynthate. According to the three models, the improvement coefficients of available nitrogen and available phosphorous and the dry weight of Festuca arundinacea achieve the highest value when cow dung is $0.8 \mathrm{~kg}$, which is the maximum amount of cow dung.

2) The contribution of the component ratio to the improvement coefficients of available nitrogen and available phosphorous rank second, and its contribution to the dry weight of Festuca arundinacea ranks first. The follyfermented sea fish waste and shellfish trash, on which many strains that can control their osmotic pressure by themselves, and the special active matter that is produced by these strains that are adnascent the host or symbiont microorganism is rich in complex organics, such as proteins, fats, bony scale, carapace and so on. For example, Shewanella colwelliana and Vibrio alginolyticus, which were isolated from Crassostrea Virgilica, can produce a type of acidic exopolysaccharides (molecular weight: $6390 \mathrm{kD}$ ), which are formed by mannitol, glucose, galactose, amino ribose, arabinose, xylose and pyruvate. This acidic exopolysaccharide solution has good rheological behavior. In addition, the acidic exopolysaccharides will resolve into many bioactive substances, such as the amino polysaccharides chitin and chitosan, and lay the material foundation for the formation of soil aggregates. These two types of specific polymer polysaccharides of nitrogen compounds, particularly the chemical structure of chitin, is similar to cellulose. These polysaccharides are oppositely charged against saline soil after mixing with saline soil, and its binding force should be stronger than the absorbability of salt ions. These two types of specific polymer polysaccharides of nitrogen compounds can activate the stimulated enzymes of proteins in plant cells and help to produce phosphorylation reactions, plant anti-interferons and phenolic compounds to reduce salt stress. In contrast, the purple membrane that is formed by halophilic bacteria has an $\mathrm{H}^{+}$ pump function, which can produce an electrochemical potential, secrete halophilic enzyme and is rich in acidic amino acids. The bacteria can directly use this type of energy to synthesize some active matter, such as ATP (adenosine triphosphate). This membrane is not only able to compensate for the lack of dissolved oxygen and energy in the oxidation of the compost but also can concentrate salt $\mathrm{K}+$ and exclude $\mathrm{Na}+$ to provide energy for the biological absorption of nutrients, playing a role as a soil biological modifier for saline soil. There are many types of halophilic bacteria. Among these bacteria, the extreme halobacteria can remain active in the conditions of $2.5-5.2 \mathrm{mmol} / \mathrm{L} \mathrm{NaCl}$ and $55^{\circ} \mathrm{C}-85^{\circ} \mathrm{C}$. At high temperatures $\left(40^{\circ} \mathrm{C}-50^{\circ} \mathrm{C}\right)$, the predominant flora are optimized and the biological and non-biological mutual feedback of biological regulation, which the biological factors and non-biological factors feedback to each other, is strengthened. The sawdust functions as an input carbon source for the predominant flora, which enhances carbon adsorption to ammonia and accelerates the conversion of complex organics. According to the three regression models, we can derive the following conclusion: $X_{21}$ component ratio (sea fish waste, 5:shellfish trash, 4:sawdust, 1) has the best contribution to the dry weight of Festuca arundinacea and to the improvement coefficients of the available nitrogen and available phosphorous; thus, the " $5: 4: 1$ " ratio was determined to be the optimum component ratio. Comparing the four composting components, the $X_{22}$ component ratio (sea fish waste, 8: shellfish trash, 1: sawdust, 1) has the lowest contribution coefficient for all the objective functions. With the improvement of the contents of the shellfish residue, the contribution coefficient of the shellfish trash also increased. This result indicates that the composting achieve- 
ment has a close positive correlation with the content of shellfish trash and that the contents of the shellfish residue play a key role in the composting achievement.

3) The contribution of saline soil or silts to the improvement coefficient of available nitrogen and available phosphorous and to the dry weight of Festuca arundinacea remain third. From the coefficient of the regression model of nitrogen and phosphorus, the author draws the conclusion that the contribution of $X_{12}$ (the weight ratio of saline soils and silts) to the improvement coefficients of nitrogen and phosphorus accounts for $31.77 \%$ and 33.33\% of cow dung, respectively. This result explains the significant correlation between the flora of sediment and the nitrogen or phosphorous in the soil release test. In contrast, the contribution to the dry weight of Festuca arundinacea is indistinctive. With the increase of the amount of sediment, both the increments of nitrogen and phosphorus and the dry weight of Festuca arundinacea are highly significantly or have significant negative growth, respectively. This result indicates that the Haihe River sediment can only be used as a halophilic bacterium agent and that the utilization of sediment must be limited. The sediment of the Haihe River is rich in some simple organisms, such as active proteases, bone phosphates, chitin, organic acids, carbon and so on, as well as some inorganic substances, such as carbonate, nitrogen, phosphorous and so on. Specific biological communities have adapted to the recorded alternating environment; however, this environment also contains much exchangeable sodium and heavy metals (Table 3), whose concentrations are beyond "soil environmental quality standards" (GB15618-1995). According to the research of Wu Qing et al., the enrichment effect and the transfer effect of Festuca arundinacea on $\mathrm{Cr}, \mathrm{Cd}$ and $\mathrm{Zn}$ is obvious; however, the rejection of Ni and Mn by Festuca arundinacea is significant. Because the activity of its dehydrogenase is particularly sensitive to heavy metals, the activity of Festuca arundinacea is negatively correlated with concentrations of heavy metals. Clearly, this type of toxicology rejection mechanism affects the effectiveness of the biological activity and nutrients. Thus, in the form of a vaccination, we use its extreme and numerous sexual reproduction to avoid reducing the dry weight of Festuca arundinacea. According to the three regression models, the contribution coefficients of $X_{12}$ (weight ratio of saline soils and silts, 8:2) to the available nitrogen, available phosphorous and the dry weight of Festuca arundinacea are all the maximum in all weight ratios of saline soil and silts. The other ratios that were examined have a negative impact on the target value; thus, the author determined that the $X_{12}$ proportion is the optimum selection.

\subsection{The Characterization of Microorganisms}

Through the preliminary identification of the bacteria genera in the test soil, we found that the microorganisms in the test soil are primarily composed of lactobacillus and bacillus genera, as well as successfully isolated halophilic species, such as halobacterium, acinetobacter, microbacterium Orla-Jensen and so on. Moreover, we isolate three types of actinomyces, whose dominant bacteria are streptomyces, and a small amount of fungi and penicillium genera. This result shows clearly that as long as the growing medium precisely assembles what the microorganisms and plants require for survival and selects for suitable species, the key issues of saline soil production medium conditions and the lack of biological species can be resolved. These requirements are measured by examining the available nutrients, the dry weight of test plants and the vitality of the biodiversity. These flora and fauna, whose cells have electrostatic attraction, and the metabolites of microorganisms (polysaccharides, polyamino acids and so on, which are recognized extracellular polymer substances that are abbreviated EPS) can cause soil particle cohesion, accelerate the formation of soil aggregates and the release of nutrients, and change the ionization balance of the toxic ions, such as $\mathrm{Na}^{+}, \mathrm{Cl}^{-}, \mathrm{SO}_{4}^{2-}$ and so on in the saline soil environment [20]. Finally, this ability is reflected in the improvement of available nitrogen and phosphorus, whose values are 1.99 and 1.93 , respectively, and the dry weight of Festuca arundinacea is $236.83 \mathrm{~g} \cdot \mathrm{m}^{-2}$.

\section{Conclusions}

1) For ecosystem degradation that is caused by salinization, the loss of species that humans require and the growth medium of these species are the main impediments to recovering soil productivity and the key problem that must be resolved. Clearly, it is advantageous to use biotic populations of the sediment in the Haihe river estuary to vaccinate for saline soil and then to vaccinate with the compost that is composed of sea fish waste, shellfish trash, sawdust and cow dung. Then, using the redundant structure of the natural formation to significantly improve the ecological structure of soil will compensate for the defect problem of the original medium biology and of the nutrition structure to become an effective method of improving saline soil. 
2) After analyzing the contribution value of every assembly factor and target, the author concludes the following: (a) The rank of the contribution of each assembly factor to nitrogen and phosphorous is as shown below: $X_{3}$ (cow dung) $>X_{2}$ (component ratio) $>X_{1}$ (weight ratio of saline soil and silts). (b) The rank of the contribution of each assembly factor to the dry weight of Festuca arundinacea is as shown below: $X_{2}>X_{3}>X_{1}$. The contribution of cow dung to the improvement of available nitrogen and available phosphorous and to the dry weight of Festuca arundinacea is first and second, respectively. The contribution of cow dung is proportional to its dosage. (c) In the four types of component ratios, the contribution of $X_{22}$ (sea fish waste, 8:shellfish trash, 1:sawdust, 1) to all targets is the lowest. Because the correlation between the target and the amount of shellfish trash is significantly positive, increasing the dosage of shellfish trash has a significant positive correlation with the composting achievement. (d) The contribution of the weight ratio of saline soil and silts to all the target value ranks third, and the contribution of $X_{12}$ (weight ratio of saline and silts, 8:2) is the best in all the levels of the weight ratios. If the contents are relatively low, then the contribution of sediment is not significant; if the contents are relatively high, then the contribution of sediment is negative. Thus, the Haihe River sediment can only be used as a halophilic bacterium agent, and the utilization of sediment must be limited.

3) The assembly that has the best contribution to nitrogen, phosphorous and the dry weight of Festuca arundinacea in the 64 types of permutations and combinations is as follows: $X_{12}$ (weight ratio of saline and silts, 8:2) $+X_{21}$ (component ratio, sea fish waste, 5:shellfish trash, 4:sawdust, 1) $+X_{3}$ (cow dung, $0.8 \mathrm{~kg}$, accounting for $10 \%$ of the total weight of $X_{1}+X_{2}$ ). In this composition, the improvement coefficient of available nitrogen is 1.99 , the improvement coefficient of available phosphorous is 1.93, and the dry weight of Festuca arundinacea in the unit area is $238.83 \mathrm{~g} \cdot \mathrm{m}^{-2}$. This conclusion has been thoroughly and repeatedly verified and can provide a basis for the demonstration of coastal saline soil improvement.

\section{Acknowledgements}

This work was supported by Tianjin Science and Technology Support Program Key Projects [08ZCJYSF02500] and Tianjin Science and Technology Commission of Science and Technology Support Program [12ZCZDSF01900]. The authors appreciate them for providing the financial support for our research.

\section{References}

[1] Martens, D.A. and Suarez, D.L. (1997) Selenium Speciation of Soil/Sediment Determined with Sequential Extractions and Hydride Generation Atomic Absorption Spectrophotometry. Environmental Science and Technology, 31, 133-139. http://dx.doi.org/10.1021/es960214+

[2] Citterio, S., Aina, R., Labra, M., Ghiani, A., Fumagalli, P., Sgorbati, S. and Santagostino, A. (2002) Soil Genotoxicity Assessment: A New Strategy Based on Biomolecular Tools and Plant Bioindicators. Environmental Science and Technology, 36, 2748-2753. http://dx.doi.org/10.1021/es0157550

[3] Gao, Y.-C., Wang, J.-N., Xu, J.-B., Kong, X., Zhao, L. and Zeng, D.-H. (2013) Assessing the Quality of Oil-Contaminated Saline Soil Using Two Composite Indices. Ecological Indicators, 24, 105-112. http://dx.doi.org/10.1016/j.ecolind.2012.06.005

[4] Wong, V.N.L., Dalal, R.C. and Greene, R.S.B. (2008) Salinity and Sodicity Effects on Respiration and Microbial Biomass of Soil. Biology and Fertility of Soils, 44, 943-953. http://dx.doi.org/10.1007/s00374-008-0279-1

[5] Pisinaras, V., Tsihrintzis, V.A., Petalas, C. and Ouzounis, K. (2010) Soil Salinization in the Agricultural Lands of Rhodope District, Northeastern Greece. Environmental Monitoring and Assessment, 166, 79-94. http://dx.doi.org/10.1007/s10661-009-0986-6

[6] Yao, L.-X., Li, G.-L., Tu, S.-H., Gavin, S. and He, Z.-H. (2007) Salinity of Animal Manure and Potential Risk of Secondary Soil Salinization through Successive Manure Application. Science of the Total Environment, 383, 106-114. http://dx.doi.org/10.1016/j.scitotenv.2007.05.027

[7] Zalidis, G. (1998) Management of River Water for Irrigation to Mitigate Soil Salinization on a Coastal Wetland. Journal of Environmental Management, 54, 161-167. http://dx.doi.org/10.1006/jema.1998.0226

[8] Russak, A. and Sivan, O. (2010) Hydrogeochemical Tool to Identify Salinization or Freshening of Coastal Aquifers Determined from Combined Field Work, Experiments, and Modeling. Environmental Science \& Technology, 44, 40964102. http://dx.doi.org/10.1021/es1003439

[9] Carol, E., Kruse, E. and Mas-Pla, J. (2009) Hydrochemical and Isotopical Evidence of Ground Water Salinization Processes on the Coastal Plain of Samborombon Bay, Argentina. Journal of Hydrology, 365, 335-345.

http://dx.doi.org/10.1016/j.jhydrol.2008.11.041 
[10] Lakhdar, A., Rabhi, M., Ghnaya, T., Montemurro, F., Jedidi, N. and Abdelly, C. (2009) Effectiveness of Compost Use in Salt-Affected Soil. Journal of Hazardous Materials, 171, 29-37. http://dx.doi.org/10.1016/j.jhazmat.2009.05.132

[11] de Paz, J.M., Visconti, F., Zapata, R. and Sanchez, J. (2004) Integration of Two Simple Models in a Geographical Information System to Evaluate Salinization Risk in Irrigated Land of the Valencian Community, Spain. Soil Use and Management, 20, 333-342. http://dx.doi.org/10.1079/SUM2004265

[12] Lakhdar, A., Hafsi, C., Rabhi, M., Debez, A., Montemurro, F., Abdelly, C., Jedidi, N. and Ouerghi, Z. (2008) Application of Municipal Solid Waste Compost Reduces the Negative Effects of Saline Water in Hordeum maritimum L. Bioresource Technology, 99, 7160-7167. http://dx.doi.org/10.1016/j.biortech.2007.12.071

[13] Lakhdar, A., Falleh, H., Ouni, Y., Oueslati, S., Debez, A., Ksouri, R. and Abdelly, C. (2011) Municipal Solid Waste compost Application Improves Productivity, Polyphenol Content, and Antioxidant Capacity of Mesembryanthemum edule. Journal of Hazardous Materials, 191, 373-379. http://dx.doi.org/10.1016/j.jhazmat.2011.04.092

[14] Tejada, M., Garcia, C., Gonzalez, J.L. and Hernandez, M.T. (2006) Use of Organic Amendment as a Strategy for Saline Soil Remediation: Influence on the Physical, Chemical and Biological Properties of Soil. Soil Biology \& Biochemistry, 38, 1413-1421. http://dx.doi.org/10.1016/j.soilbio.2005.10.017

[15] Datta, A., Yeluripati, J.B., Nayak, D.R., Mahata, K.R., Santra, S.C. and Adhya, T.K. (2013) Seasonal Variation of Methane Flux from Coastal Saline Rice Field with the Application of Different Organic Manures. Atmospheric Environment, 66, 114-122. http://dx.doi.org/10.1016/j.atmosenv.2012.06.008

[16] Chi, J. (2009) Vertical Fluxes and Accumulation of Organochlorine Pesticides in Sediments of Haihe River, Tianjin, China. Bulletin of Environmental Contamination and Toxicology, 82, 510-515. http://dx.doi.org/10.1007/s00128-008-9630-3

[17] Sun, S.J., Huang, S.L., Sun, X.M. and Wen, W. (2009) Phosphorus Fractions and Its Release in the Sediments of Haihe River, China. Journal of Environmental Sciences-China, 21, 291-295. http://dx.doi.org/10.1016/S1001-0742(08)62266-4

[18] Bossuyt, H., Denef, K., Six, J., Frey, S.D., Merckx, R. and Paustian, K. (2001) Influence of Microbial Populations and Residue Quality on Aggregate Stability. Applied Soil Ecology, 16, 195-208. http://dx.doi.org/10.1016/S0929-1393(00)00116-5

[19] Claus, H., Akca, E., Debaerdemaeker, T., Evrard, C., Declercq, J.P. and Konig, H. (2002) Primary Structure of Selected Archaeal Mesophilic and Extremely Thermophilic Outer Surface Layer Proteins. Systematic and Applied Microbiology, 25, 3-12. http://dx.doi.org/10.1078/0723-2020-00100

[20] Zhang S. and Wang C. (2007) Progress of Research on the Structure and Bioactivities of Marine Microbial Exopolysaccharide. Microbiology, 34, 153-156. 